\title{
Bottlenose Dolphin Calf Initiated Pectoral Fin Contact Exchanges with Mother, Other Kin, and Non-Kin
}

\author{
Kathleen M. Dudzinski ${ }^{1, *}$, Christine A. Ribic ${ }^{2}$, Heather M. Manitzas Hill ${ }^{3}$, and Teresa T. Bolton ${ }^{4}$ \\ ${ }^{1}$ Dolphin Communication Project, Port Saint Lucie, Florida \\ ${ }^{2}$ U.S. Geological Survey, Wisconsin Cooperative Wildlife Research Unit, Department of Forest and Wildlife Ecology, University \\ of Wisconsin, Madison, Wisconsin \\ ${ }^{3}$ Psychology Department, St. Mary's University, San Antonio, Texas \\ ${ }^{4}$ The Roatan Institute for Marine Sciences, Anthony's Key Resort, Sandy Bay, Roatan, Honduras \\ *Corresponding author (Email: kathleen@dcpmail.org)
}

Citation - Dudzinski, K. M., Ribic, C. A., Manitzas Hill, H. M., \& Bolton, T. T. (2021). Bottlenose dolphin calf initiated pectoral fin contact exchanges with mother, other kin, and non-kin. Animal Behavior and Cognition, 8(3), 376-390. https://doi.org/10.26451/abc.08.03.04.2021

\begin{abstract}
For dolphins, the strongest bond documented is typically that between a mother and her pre-weaned offspring, but outside of the maternal relationship, our knowledge of calf behavior is limited. We examined how 23 bottlenose dolphin (Tursiops truncatus) calves (11 females and 12 males from 9 matrilines) initiated pectoral fin contact (PFC) exchanges with their mothers and kin $(n=362)$ versus with non-kin $(n=950)$. Calves initiated PFC exchanges with preferred partners (primarily their mothers) over individuals who were simply available to them. For calves with mothers as their only kin available, there was a difference in how they shared PFC with non-kin adults versus non-kin young. A calf was twice as likely to initiate PFC with an adult (mother or adult non-kin) as with another young dolphin. Male and female calves were different in how they initiated PFC with kin and non-kin, which supports previous research that identified a sex difference in calf behavior. These results support the observation that kin and non-kin dolphins share PFC differently. It is also likely that kin (mothers and calves, siblings, etc.) use other forms of contact to share information and potentially develop their relationships. Understanding all types of tactile contact would facilitate a more detailed understanding of how touch might be used by dolphins when relationships are established and maintained.
\end{abstract}

Keywords - Pectoral fin contact, Mother-calf dyads, Bottlenose dolphins, Tactile contact, Behavior, Non-kin

For most social mammals, the strongest bond documented is that between a mother and her offspring (Hinde, 1970), and this is potentially true for dolphins as well (Gubbins et al., 1999; Mann et al., 2000; Mann \& Smuts, 1999). The mother-calf bond is critical for offspring survival with dolphin calves weaned typically at two to four years of age (Wells et al., 1987). This bond is also crucial for future network success for male and female calves (Gibson \& Mann, 2008; Stanton et al., 2011). Calves learn how to forage (e.g., Tursiops aduncus [Sargeant \& Mann, 2009], Orcinus orca [Brent et al., 2015; Guinet, 1991; Guinet \& Bouvier, 1995]) and navigate social networks from their mothers during their first few years of life ( $T$. aduncus, Gibson \& Mann, 2008; Krzyszczyk et al., 2017; Stanton et al., 2011).

Outside of the maternal relationship, our knowledge of calf behavior is limited, though some exceptions are available in the literature. Mann and colleagues have focused extensively on calf interactions, behavioral development, and network associations for Indo-Pacific bottlenose dolphins (T. aduncus, e.g., Gibson \& Mann, 2008; Krzyszczyk et al., 2017; Mann et al., 2000; Mann \& Smuts, 1998, 1999; Sargeant \& Mann, 2009; Stanton et al., 2011). Bender et al. (2009) provided evidence of teaching in Atlantic spotted dolphins (Stenella frontalis) by adult females foraging with their calves. The synchronous and asynchronous behaviors by calves with and without their mothers within the context of how the mother/calf bond changed over time has also been examined (Miles \& Herzing, 2003). In contrast, Levengood and Dudzinski (2015) 
focused on calf associates to examine how bottlenose dolphin (T. truncatus) calves interacted with kin and non-kin peers and found variability ranging from none to several associates with both kin and non-kin conspecifics. Utilizing a four-year subset of the current study's data during which more non-kin than kin peers were available to the seven calves observed, Levengood and Dudzinski (2015) found that three calves preferred kin while the other four showed no bias. These results suggested that outside the mother-calf bond there was no conclusive preference between kin and non-kin associates. Thus, it is likely that other factors including age, personality, and sociality have more impact on associations.

The majority of historic and current literature related to preferences in tactile exchanges (i.e., grooming) between sibling versus non-sibling (i.e., between kin versus non-kin) conspecifics is for primate research (Janus, 1989; Kapsalis \& Berman, 1996; Schino, 2001; Silk, 2002; Wu et al., 2018), although the mangrove killifish (Kryptolebias marmoratus) also preferentially associate with kin over non-kin and show less aggression toward related conspecifics (Edenbrow \& Croft, 2012). Grooming is likely the most widely studied primate social behavior and is regarded as a good index of affiliative relationships in primates (Schino, 2001; Silk, 2002). In a meta-analysis of 27 primate groups of 14 different species, Schino (2001) confirmed that attraction to high ranking associates, to kin, and competition for grooming partners are affected by the distribution of grooming between individuals. One of the few studies to look at immature siblings versus non-siblings, Janus (1989) examined grooming, play, and proximity among Rhesus monkeys (Macaca mulatta): play was equal between kin and non-kin, but more time was spent grooming and in proximity with siblings over non-siblings. Additionally, Janus (1989) observed that sibling interactions were more reciprocal than those of non-siblings.

Play behavior between and among calves has been studied systematically for several dolphin species, including bottlenose dolphins (T. truncatus, Cappiello et al., 2018; Kuczaj et al., 2006; Kuczaj \& Eskelinen, 2014; Paulos et al., 2010), spinner dolphins (S. longirostris, Silva et al., 2005), Atlantic spotted dolphins (Miles \& Herzing, 2003), and rough-toothed dolphins (Steno braedenensis, Kuczaj \& Yeater, 2007). Kuczaj et al. (2006) showed that play is contagious among all age groups while Kuczaj and Eskelinen (2014) confirmed that play is more complex when there are more same-aged, same-sex individuals in a group. Miles and Herzing (2003) peripherally examined calf attention to objects during playful or social contexts but did not clarify if these observations were in association with maternal activity or during solitary or calf-calf social behavior. Greene et al. (2011) comparatively examined object play in Atlantic spotted and bottlenose dolphins in different settings, though play was not documented only for calves but for all age groups. Cappiello et al. (2018) extended Greene et al.'s research on the same group of bottlenose dolphins examining all age groups and their prevalence of object play; calves preferred same-sex, same-age partners when engaged in social play that involved an object. Cappiello et al.'s results were similarly observed for rhesus monkeys three decades earlier by Janus (1989); these primates played equally with kin and non-kin but preferred same-aged non-siblings more than other non-siblings. Even given these studies on dolphin calf play behavior, there is a paucity of data on how calves use tactile contact during play, or during other contexts.

Dudzinski and colleagues have been investigating the role of pectoral fin contact between dolphins for several species in numerous settings (Dudzinski et al., 2009, 2010, 2012, 2013; Dudzinski \& Ribic, 2017; Dudzinski et al., 2021; Evans-Wilent \& Dudzinski, 2013). This research has yielded a plethora of information about how dolphins share pectoral fin contact: it is a conserved behavior across species and locations (Dudzinski et al., 2009, 2010); rates of contact are consistent across populations with primarily non-kin sharing pectoral fin contacts as a social tool for bond formation and maintenance (Dudzinski \& Ribic, 2017). Most recently, Dudzinski et al. (2021) focused on mother-calf dyads and maternal-focused exchanges of pectoral fin contacts. Although shared contacts among kin were drastically reduced as compared with non-kin shared PFC, this study found that adult female dolphins display individual differences in PFC patterns with their calves, which were related to maternal styles. Where Dudzinski et al. (2021) focused on the maternal perspective of pectoral fin contacts, the current study sought to understand how calves might share pectoral fin contacts with kin and non-kin. 


\section{Current Study Objectives}

We addressed the following questions in this study: 1) How are calves sharing pectoral fin contact with kin and non-kin dolphins? 2) Do calves share pectoral fin contact with their mothers the same as with non-kin dolphins? 3) Do dolphin calves share pectoral fin contact with their different kin groups (e.g., mother vs young kin) similarly to how they share pectoral fin contact with non-kin? 4) Does calf sex affect how calves initiate pectoral fin contact with kin versus non-kin?

\section{Method}

Data specific to pre-weaned, calf-initiated pectoral fin contact (PFC) exchanges are part of longterm, comparative research into dolphin communication by the Dolphin Communication Project (e.g., Dudzinski et al., 2009, 2010, 2013; Dudzinski \& Ribic, 2017; Evans-Wilent \& Dudzinski, 2013). Permission to observe and collect data on the dolphins at The Roatán Institute for Marine Sciences (RIMS), Anthony's Key Resort (AKR), Roatán, Honduras, was granted by the facility; RIMS holds current permits from the Honduras government for housing dolphins.

\section{Study Site and Population}

Observational data were collected on video at RIMS annually for 16 years (2003 to 2018, see Appendix in Dudzinski et al., 2021). This dolphin group is housed in coastal sea pens adjacent to Bailey's Key, along the NW side of Roatan, located inside Roatan's fringing reef (see Dudzinski et al., 2010 for additional site details). Dolphin ages ranged from neonate to 40+ years; the general social dynamic was similar to that observed for wild bottlenose dolphins (e.g., Connor, Smolker et al., 2006; Kogi et al., 2004). The total number of dolphins per observation session varied depending on coordination with other facilities managed by RIMS, and by recorded deaths and births. Offspring from 10 matrilines were available for observation (Table 1). The typical inter-birth interval for wild bottlenose dolphins is three years (Mann \& Smuts, 1999; Wells, 2014; Wells et al., 1987) and it is roughly the same for dolphins in managed care (Cornell et al., 1987; Jaakkola \& Willis, 2019). Once weaned, male bottlenose dolphins often form juvenile bachelor groups that are separate from adult and juvenile female groups (Krzyszczyk et al., 2017; Wells, 2014). Single births are typical for dolphins; thus, because of the inter-birth interval, calves will not typically have other calf-aged maternal siblings as potential peers.

No video data were available for some calves at specific age classes (Table 2); for example, Tilly was not observed as a C2 and Calli, Elli, and Champ were not observed as a C1. Also, PFC data for two male calves (Ronnie and Osgood) from one mother (Rita) were limited and, therefore, her matriline was not included in further analyses (Table 2). Otherwise, all calves were available for observation at each identified age (Table 2) and were video recorded, though every calf did not interact with every other available individual, kin or non-kin.

\section{Data Collection}

Dyadic dolphin interactions and their behavioral exchanges were recorded on video with concurrent stereo audio while underwater (Dudzinski et al., 1995). PFC exchanges were event sampled from video collected via a focal follow protocol; see Dudzinski et al. (2009) and Dudzinski and Ribic (2017) for protocol details. Each contact between one dolphin's pectoral fin and another dolphin's body (including the pectoral fin) was documented (see Dudzinski et al., 2009 for definitions); for this study, calf-initiated and -received PFCs were examined. 
Table 1

Matrilines with Identified Offspring (calves) Available for Observation Across all Years (2003-2018) and the Number of Documented Pectoral Fin Contact Exchanges for Each Mother/calf Pair

\begin{tabular}{|c|c|c|c|}
\hline Mother & Calf name (sex) & Calf ages observed & $\begin{array}{c}\text { Pectoral Fin Contact exchanges } \\
\text { observed (regardless of Initiator) }\end{array}$ \\
\hline \multirow{5}{*}{ Alita } & Fiona $(\mathrm{F})$ & $\mathrm{C} 1, \mathrm{C} 2, \mathrm{C} 3, \mathrm{~J}, \mathrm{~S}$ & $0,14,2,0,0$ \\
\hline & Anthony (M) & $\mathrm{C} 1, \mathrm{C} 2, \mathrm{C} 3, \mathrm{~J}$ & $7,2,0,0$ \\
\hline & Cortez (M) & $\mathrm{C} 1, \mathrm{C} 2, \mathrm{~J}$ & $\mathrm{nv}, 0, \mathrm{nv}$ \\
\hline & Lenca (M) & $\mathrm{C} 2, \mathrm{C} 3, \mathrm{~J}, \mathrm{~S}$ & $1,1,0,0$ \\
\hline & Dory (F) & $\mathrm{C} 1, \mathrm{C} 2$ & 1,30 \\
\hline Bailey* & Tank & $\mathrm{C} 1$ & 43 \\
\hline \multirow{5}{*}{ Carmella } & Ritchie (M) & $\mathrm{J}, \mathrm{S}, \mathrm{A}$ & $2,0,0$ \\
\hline & $\operatorname{Ken}(\mathrm{M})$ & $\mathrm{C} 1, \mathrm{C} 2, \mathrm{C} 3, \mathrm{~J}, \mathrm{~S}$ & $0,3,1,0,0$ \\
\hline & Dixon $(\mathrm{M})$ & $\mathrm{C} 1, \mathrm{C} 2, \mathrm{C} 3, \mathrm{~J}, \mathrm{~S}$ & $0,2,0,0,0$ \\
\hline & Elli $(\mathrm{F})$ & $\mathrm{C} 2, \mathrm{C} 3, \mathrm{~J}$ & $0,0,0$ \\
\hline & Stan $(\mathrm{M})$ & $\mathrm{C} 1, \mathrm{C} 2$ & 0,2 \\
\hline \multirow{3}{*}{ Cedeña } & Bailey (F) & $\mathrm{C} 1, \mathrm{C} 2, \mathrm{C} 3, \mathrm{~J}, \mathrm{~S}, \mathrm{~A}$ & $0,10,0,2,0,1$ \\
\hline & Pigeon $(\mathrm{F})$ & $\mathrm{C} 1, \mathrm{C} 2, \mathrm{C} 3, \mathrm{~J}$ & $0,22,2,0$ \\
\hline & Calli (F) & $\mathrm{C} 2, \mathrm{C} 3, \mathrm{~J}$ & $2,0, \mathrm{nv}$ \\
\hline $\mathrm{GeeGee}^{* *}$ & Mika (F) & $\mathrm{C} 3, \mathrm{~J}, \mathrm{~S}, \mathrm{~A}$ & $2, \mathrm{nv}, \mathrm{nv}, \mathrm{nv}$ \\
\hline \multirow{5}{*}{ Gracie } & Maury (F) & $\mathrm{C} 2, \mathrm{C} 3, \mathrm{~J}, \mathrm{~S}, \mathrm{~A}$ & $19,1,1,1,7$ \\
\hline & Jack (M) & $\mathrm{C} 1, \mathrm{C} 2, \mathrm{C} 3, \mathrm{~J}$ & $0,3,23,0$ \\
\hline & Luna $(\mathrm{F})$ & $\mathrm{C} 1$ & 20 \\
\hline & Tilly (F) & $\mathrm{C} 1, \mathrm{C} 2, \mathrm{C} 3, \mathrm{~J}, \mathrm{~S}, \mathrm{~A}$ & $0, \mathrm{nv}, 8,5,0,3$ \\
\hline & Shawn $(M)$ & $\mathrm{C} 1, \mathrm{C} 2$ & 3,25 \\
\hline Maury* & Champ (M) & $\mathrm{C} 2, \mathrm{C} 3, \mathrm{~J}$ & $0,1,0$ \\
\hline \multirow{3}{*}{ Mika* } & Mickey (M) & $\mathrm{C} 1, \mathrm{C} 2, \mathrm{C} 3, \mathrm{~J}$ & $0,17,0,0$ \\
\hline & Poli (F) & $\mathrm{C} 1, \mathrm{C} 2, \mathrm{C} 3, \mathrm{~J}, \mathrm{~S}$ & $\mathrm{nv}, \mathrm{nv}, \mathrm{nv}, 1,0$ \\
\hline & $\operatorname{Mac}(\mathrm{M})$ & $\mathrm{C} 1, \mathrm{C} 2, \mathrm{C} 3, \mathrm{~J}$ & $6,5,0,0$ \\
\hline \multirow{3}{*}{ Mrs. B. } & French $(\mathrm{M})$ & $\mathrm{C} 1, \mathrm{C} 2, \mathrm{C} 3, \mathrm{~J}, \mathrm{~S}, \mathrm{~A}$ & $8,4,2,0,0,0$ \\
\hline & Margarita $(\mathrm{F})$ & $\mathrm{C} 1, \mathrm{C} 2, \mathrm{C} 3, \mathrm{~J}, \mathrm{~S}$ & $8,6,0,2,0$ \\
\hline & Vin $(M)$ & $\mathrm{C} 1, \mathrm{C} 2, \mathrm{C} 3, \mathrm{~J}$ & $0,9,2,0$ \\
\hline \multirow{3}{*}{ Rita } & Tela $(\mathrm{F})$ & $\mathrm{J}$ & 0 \\
\hline & Ronnie (M) & $\mathrm{C} 1, \mathrm{C} 2, \mathrm{C} 3, \mathrm{~J}, \mathrm{~S}, \mathrm{~A}$ & $4,0,0,0, \mathrm{nv}, \mathrm{nv}$ \\
\hline & Osgood (M) & $\mathrm{C} 1$ & 9 \\
\hline
\end{tabular}

Note. Abbreviations are: $\mathrm{C} 1$ is one-year-old calf; $\mathrm{C} 2$ is two-year-old calf; $\mathrm{C} 3$ is three-year-old calf; and $\mathrm{F}=$ female, $\mathrm{M}=$ male, $\mathrm{A}=$ adult, $\mathrm{S}=$ subadult, $\mathrm{J}=$ juvenile. Use of "nv" indicates no video collected for that calf at that age with mother; mother and calf were not observed or video-recorded together at the calf age indicated. A " 0 " in the Pectoral Fin Contact exchanges column indicates the calf at the indicated age was available for observation and was video-recorded with the mother but that no PFC were documented on video. From Dudzinski et al. (in press), with permission.

* indicates second generation adult female matrilines.

** GeeGee was present during observations only for Mika as a C3. 


\section{Definitions}

Because this paper extends our examination of PFC specifically to interactions involving calves, our definitions were consistent with previous work (e.g., Dudzinski et al., 2009, 2010, 2012, 2013; Dudzinski \& Ribic, 2017). As in Dudzinski et al. (2021), kin relations were assessed based on observed maternal relatedness, not genetics. Though our early studies examining PFC exchanges included four observed dolphin age classes (calf, juvenile, subadult, adult, e.g., Dudzinski et al., 2010; Dudzinski \& Ribic, 2017), in this study we combined the juvenile and subadult age classes into a single young adult class to yield three dolphin age categories (calf, young adult, adult) to be consistent with those used to study wild dolphins (Connor, Smolker et al., 2006; Kogi et al., 2014; Wells et al., 1987); detailed definitions are available in Dudzinski et al. (2021).

\section{Table 2}

Female and Male Bottlenose Dolphin Calves Available for Observation from 2003-2018

\begin{tabular}{cccc}
\hline & Females & & Males \\
\hline Calf & Ages Observed & Calf & Ages Observed \\
\hline Bailey & C1, C2, C3, J, S, A & Anthony & C1, C2, C3, J \\
Calli & C2, C3 3 , 3, J \\
Dory & C1, C2 & Champ & C1, C2, C3, J, S \\
Elli* & C2, C3, J & Dixon & C1, C2, C3, J, S, A \\
Fiona & C1, C2, C3, J, S & Jack & C1, C2, C3, J \\
Luna & C1 & Ken & C1, C2, C3, J, S \\
Margarita & C1, C2, C3, J, S & Lenca* & C2, C3, J, S \\
Maury & C3, J, S, A & Mac & C1, C2, C3, J \\
Mika & C3, J, S, A & Mickey & C1, C2, C3, J \\
Pigeon & C1, C2, C3, J & Osgood & C1 \\
Poli & C3, J, S & Ronnie & C3, J, S \\
Tilly & C1, C3, J, S, A & Shawn & C1, C2
\end{tabular}

\footnotetext{
* Not included in analyses due to low sample size of PFC contact. Abbreviations same as in Table 1. J and S were combined as a young adult age category for statistical analyses.
}

\section{Statistical Analyses}

The sampling unit was the identified calf (initiator or receiver) for each PFC exchange. The dolphin with which the calf interacted was categorized by sex, age class, and kin or non-kin. A contact exchange was classified as kin if the dolphin with whom the calf interacted was a sibling, aunt, mother, or grandmother of the calf and non-kin if otherwise.

Before analysis, we looked at the structure of the data in terms of who the calves interacted with. Specifically, we were interested in understanding if there were individual dolphins that provided the majority of interactions (i.e., influential dolphins that might affect the analyses). We used crosstabulation and summary statistics to determine how many individual dolphins a calf interacted with and how many calves an individual dolphin interacted with. 
We used the 23 calves that had approximately 20 or more interactions with other known dolphins for analysis, as this allowed reliable estimation of the proportions of interactions for the different kin and non-kin age classes. All calves had their mother and three non-kin dolphin age categories (calves, young adults, and adults) with which to interact (see Table A1 in the Appendix). However, calf kin and young adult kin were not always available for interaction. Therefore, the calves were divided into two general kin groups: 1) calves that had no calf kin or young adult kin to interact with (i.e., Mother-only group, $n=5$ calves) and 2) calves that had calf kin and/or young adult kin with which to interact (i.e., Young-kin group, $n=18$ ). This Young-kin group was further divided into three sub-groups: only calf kin available along with the mother ( $n=3$ calves), only young adult kin available along with the mother $(n=10)$, and both calf and young adult kin available along with the mother $(n=5)$.

We investigated two aspects of how calves shared PFC with other dolphins: with whom the calves shared PFC and how the calves shared PFC. For the first aspect of understanding with whom the calves shared PFC, we were interested in whether there were patterns related to the kin and non-kin age categories. To determine these patterns, we tested to see if the calves were sharing PFC in relation to the availability of the kin and non-kin age categories. Availability was defined for each calf and was the average proportion of individuals in the kin and non-kin age categories, averaged over sampling sessions for each calf. We compared the patterns of the calves' interactions in the Mother-only group and the three subgroups of the Young-kin group against each of the availability distributions using contingency tables. Specifically, we tested whether the proportion of calf interactions with the different kin and non-kin age categories followed the availability of the kin and non-kin age categories with a chi-square test and a simulation approach to determine significance of the test statistic; 20,000 simulations were conducted for each test (Rugg, 2003). In these tests, the null hypothesis is that calves' interactions follow the availability distributions (see Table A1). For all tests, significance was assessed with alpha set at 0.05 . We then used residual analysis (Lloyd, 1999) to understand where more and fewer interactions than expected occurred. For the residual analysis, we used residuals greater than $|1.96|(p \leq .05)$ to determine the kin and non-kin categories where more (positive residuals) and fewer (negative residuals) interactions than expected occurred. To compare results across the groups, we tabulated the kin and non-kin age categories with residuals $>|1.96|$.

We were also interested in whether having young kin available changed the propensity of a calf to interact with the mother and non-kin young dolphins, which would affect the proportion of calf interactions with the mother and non-kin young dolphins. In other words, if there are young kin available, does the calf interact less with their mother. And if there are young kin available, does the calf interact more with their young kin than young non-kin. We looked at the proportion of contact with the mother and non-kin young dolphins separately. Each analysis was done in two parts. The first analysis looked within the Young-kin group of calves to see if having calf kin, young adult kin or both available changed the proportion of contacts the focal calf had with its mother (or non-kin young dolphins; i.e., does it matter if the kin were also calves). If the influence of calf kin and young adult kin on the proportion of contacts the focal calf had with its mother (or non-kin young dolphins) was the same, this meant that the subgroups (i.e., calf kin only, young adult kin only or both available) could be combined into an overall Young-kin group (i.e., it does not matter if the kin are calves, just that there are young kin available). If this occurred, then we used the Young-kin group in the second analysis, otherwise the individual subgroups were used. The second analysis tested whether the proportion of contacts with the mother (or non-kin young dolphins) were the same for the Mother-only group and the Young-kin group (or subgroups of the Young-kin group).

Because the number of total contacts varied, we used a weighted regression model where the weights are the total number of contacts (so the calves with the most overall contacts are given more weight). The model was a generalized linear model with a binomial error structure. The response variable was the proportion of contacts that each calf had with the mother (or with young non-kin) and the explanatory variable was the calf groups. We used a $p$ of .05 for significance. Linear models were fit using glm in $\mathrm{R}$ version 3.6.2.

For the second aspect of how calves shared PFC with the different kin and non-kin age categories, we focused on how calves initiated contact. We also wanted to understand if sex of the calf affected how calves initiated contact. However, the Mother-only group was composed primarily of female calves (only 1 calf was male), which precluded consideration of sex differences in that group. In the Young-kin group, 
however, there were 7 females and 11 males so we could incorporate sex of the calf into the analysis of the Young-kin group to understand if sex of calf affected the initiation pattern.

To understand how calves in the Mother-only group initiated interactions, we first tested if the probability of initiation by the calf [P(initiator)] was the same across the three non-kin age categories (calf, young adult, and adult). If some of the non-kin age categories were not significantly different in how the calves initiated contact, we then combined those age categories that were not significantly different and compared $\mathrm{P}$ (initiator) of those non-kin age categories against $\mathrm{P}$ (initiator) with the mother.

To understand how calves in the Young-kin group initiated interactions with the kin and non-kin age categories, we used a model that included the interaction of calf sex and kin and non-kin age categories. A significant interaction would indicate that female and male calves initiated PFC differently with the kin and non-kin age categories. The model for $\mathrm{P}$ (initiator) for the Young-kin group, then, was composed of calf sex (M/F), kin and non-kin age categories, and the interaction of calf sex and kin and non-kin age categories. If the interaction was significant, we then analyzed the data by calf sex to understand the differences in how female and male calves initiated contact with the kin and non-kin age categories. Kin and non-kin age categories were young kin, mother, young non-kin, and adult non-kin.

We used a generalized linear mixed effects model (McCullagh \& Nelder, 1989) in all analyses of calf-initiated contact. The response variable was coded as " 1 " if the calf was the initiator and " 0 " if the calf was the receiver. We used a binomial error structure and Calf ID was the random effect. Calf sex and the age categories were fixed effects. We used a $p$ of .05 for significance. Linear models were fit using glmer in $\mathrm{R}$ version 3.6.2.

\section{Results}

There were 1,311 PFCs, where the initiator and receiver were known, documented for 23 calves from nine mothers between kin $(n=362)$ and non-kin $(n=949)$ (Table 3). Besides the mothers, calves interacted with nine young kin, 25 non-kin calves, 22 non-kin young adults, and 15 non-kin adults. Calves interacted with an average of 2.6 non-kin calves $(S D=1.2$, range $=1$ to 5), 3.5 non-kin young adults $(S D=$ 1.26 , range $=1$ to 6$)$, and 2.7 non-kin adults $(S D=1.5$, range $=1$ to 7$)$. Overall, individual non-kin dolphins interacted with an average of 3.0 focal calves $(S D=1.9)$. An individual non-kin calf interacted with 2.3 focal calves, on average $(S D=1.0$, range $=1$ to 4$)$. Non-kin young adults interacted with 3.0 focal calves, on average $(S D=1.9$, range $=1$ to 7$)$, and non-kin adults interacted with 3.5 focal calves, on average $(S D=$ 2.1 , range $=1$ to 8 ). There were six non-kin dolphins that interacted with $25 \%$ or more of the calves and these dolphins had, on average, 4.7 PFCs with the focal calves they interacted with $(S D=3.4)$.

\section{Patterns of Calf PFC Interaction with Dolphins by Age Class and Kin Status}

For all groups, we rejected the null hypothesis that the calves interacted with dolphins following availability (Table 4, Table A1). Of the 23 calves, $69.6 \%$ of them interacted more with their mother than expected (i.e., $n=16$ calves with significantly positive residuals in the Mother column of Table 4), $31.9 \%$ interacted more with non-kin calves $(n=9)$, and $43.5 \%$ interacted more with non-kin young adults $(\mathrm{n}=10)$ (Table 4). Of the 18 calves that had available young kin to interact with, four interacted more with their young kin $(22.2 \%)$. Overall, the calves interacted more than expected due to availability with mothers and young non-kin (i.e., non-kin calves and non-kin young adults).

Within the Young-kin group, the proportion of contacts made with the mother was the same among the three subgroups that had calf kin, young adult kin, or both available $\left(\mathrm{X}^{2}(2, N=1,118)=0.27, p=.87\right)$. However, the proportion of contacts made with the mother was different between the Mother-only group and the Young-kin group $\left(\mathrm{X}^{2}(1, N=1,312)=7.63, p=.006\right)$. The probability of a calf interacting with the mother when no young kin were available was $0.32(S D=0.25)$ while the probability that a calf interacts with the mother when there are young kin present is 0.225 . Thus, when calves only had the mother as kin to interact with, they interacted $42 \%$ more with the mother than when they also had young kin available. 
Within the Young-kin group, the proportion of contacts made with young non-kin was the same among the three subgroups that had calf kin, young adult kin, or both available $\left(\mathrm{X}^{2}(2, N=1,118)=0.23, p\right.$ $=.89)$. In addition, the proportion of contacts made with young non-kin was not different between the Mother-only group and the Young-kin group $\left(\mathrm{X}^{2}(1, N=1,312)=0.85, p=.36\right)$. Proportion of young nonkin PFCs overall was $0.63(S D=0.20)$.

\section{Table 3}

Frequency of PFC by Female and Male Bottlenose Dolphin Calves with Kin and Non-kin Partners Mother identity and group designation provided for each calf

\begin{tabular}{|c|c|c|c|c|c|c|}
\hline \multirow[b]{2}{*}{ Kin available group } & \multirow[b]{2}{*}{ Mother } & \multirow[b]{2}{*}{ Calf } & \multirow[b]{2}{*}{ Calf Sex } & \multicolumn{3}{|c|}{ Non-kin } \\
\hline & & & & Kin Total & Total & Grand Total \\
\hline \multirow{5}{*}{ Mother only Group } & Cedena & Bailey & $\mathrm{F}$ & 10 & 9 & 19 \\
\hline & Alita & Fiona & $\mathrm{F}$ & 16 & 53 & 69 \\
\hline & Gracie & Luna & $\mathrm{F}$ & 20 & 4 & 24 \\
\hline & GeeGee & Mika & $\mathrm{F}$ & 2 & 47 & 49 \\
\hline & Mrs. B. & French & M & 14 & 19 & 33 \\
\hline \multicolumn{7}{|l|}{ Young-kin Group } \\
\hline \multirow{3}{*}{$\begin{array}{r}\text { (1) Calf kin and mother } \\
\text { subgroup }\end{array}$} & Gracie & Maury & $\mathrm{F}$ & 20 & 97 & 117 \\
\hline & Gracie & Tilly & $\mathrm{F}$ & 13 & 6 & 19 \\
\hline & Mika & Mickey & M & 17 & 51 & 68 \\
\hline \multirow{10}{*}{$\begin{array}{l}\text { (2) Young adult kin and } \\
\text { mother subgroup }\end{array}$} & Cedena & Calli & $\mathrm{F}$ & 2 & 22 & 24 \\
\hline & Alita & Dory & $\mathrm{F}$ & 31 & 97 & 128 \\
\hline & Cedena & Pigeon & $\mathrm{F}$ & 26 & 16 & 42 \\
\hline & Carmella & Dixon & M & 13 & 26 & 39 \\
\hline & Gracie & Jack & M & 25 & 65 & 90 \\
\hline & Carmella & Ken & M & 10 & 59 & 69 \\
\hline & Gracie & Shawn & M & 30 & 61 & 91 \\
\hline & Carmella & Stan & M & 16 & 104 & 120 \\
\hline & Bailey & Tank & M & 43 & 50 & 93 \\
\hline & Mrs. B. & Vin & M & 13 & 39 & 52 \\
\hline \multirow{5}{*}{$\begin{array}{r}\text { (3) Calf kin, young } \\
\text { adult kin, and mother } \\
\text { subgroup }\end{array}$} & Mrs. B. & Margarita & F & 14 & 17 & 31 \\
\hline & Mika & Poli & $\mathrm{F}$ & 0 & 22 & 22 \\
\hline & Alita & Anthony & M & 9 & 52 & 61 \\
\hline & Maury & Champ & M & 6 & 24 & 30 \\
\hline & Mika & Mac & M & 12 & 9 & 21 \\
\hline
\end{tabular}

Note: The Young-kin group is a combination of three subgroups.

\section{Calf Initiator PFC Patterns}

\section{Mother-only Group}

Calves initiated contact differently with the non-kin age categories $\left(\mathrm{X}^{2}(2, N=194)=8.98, p=.011\right)$. Specifically, $\mathrm{P}$ (initiator) differed between young adult and adult non-kin (coefficient $=1.75, S E=0.64, p=$ .006 ) but not between young adult and calf non-kin (coefficient $=0.585, S E=0.38, p=.128$ ). This indicates that calf and young adults could be combined into a young non-kin category for comparison with the mother 
along with the adult non-kin category. There was a significant difference among $\mathrm{P}$ (initiator) for the mother, young non-kin, and adult non-kin $\left(\mathrm{X}^{2}(2, N=194)=22.14, p<.0001\right)$. Specifically, $\mathrm{P}$ (initiator) with the mother differed from the $\mathrm{P}$ (initiator) with young non-kin (coefficient $=-1.53, S E=0.35, p<.0001$ ) but $\mathrm{P}$ (initiator) with the mother did not differ from $\mathrm{P}$ (initiator) with adult non-kin (coefficient $=-0.04, S E=$ $0.65, p=.95$ ). The probability of a calf initiating an interaction with an adult (either the mother or adult nonkin) was 0.74 while the probability of a calf initiating an interaction with young non-kin (calves or young adults) was 0.38 . Calves were $92 \%$ more likely to initiate contact with an adult than young non-kin.'

\section{Table 4}

Summary of Deviation of Bottlenose Dolphin Calves' Interactions from Availability

\begin{tabular}{|c|c|c|c|c|c|c|c|c|}
\hline \multirow[b]{2}{*}{$\begin{array}{l}\text { Kin available } \\
\text { group }\end{array}$} & \multirow[b]{2}{*}{ Calf } & \multicolumn{3}{|c|}{ Kin } & \multicolumn{3}{|c|}{ Non-kin } & \multirow[b]{2}{*}{ Test Result } \\
\hline & & Calf & $\begin{array}{c}\text { Young } \\
\text { adult }\end{array}$ & Mother & Calf & $\begin{array}{c}\text { Young } \\
\text { adult }\end{array}$ & Adult & \\
\hline \multirow{5}{*}{ Mother only } & Bailey & NA & NA & $\mathrm{X}$ & & $(\mathrm{X})$ & & \multirow{5}{*}{$\mathrm{X}^{2}(12, N=194)=587.8, p<.001$} \\
\hline & Fiona & NA & NA & $\mathrm{X}$ & & $X$ & $(\mathrm{X})$ & \\
\hline & Luna & NA & NA & $\mathrm{X}$ & & $(\mathrm{X})$ & & \\
\hline & Mika & NA & NA & & $X$ & $X$ & $(\mathrm{X})$ & \\
\hline & French & NA & NA & $\mathrm{X}$ & & & $(\mathrm{X})$ & \\
\hline \multicolumn{9}{|l|}{$\begin{array}{l}\text { Young-kin } \\
\text { Group }\end{array}$} \\
\hline \multirow{3}{*}{$\begin{array}{l}\text { (1) Calf kin } \\
\text { and mother } \\
\text { subgroup }\end{array}$} & Maury & & NA & $\mathrm{X}$ & & $\mathrm{X}$ & $(\mathrm{X})$ & \multirow{3}{*}{$\mathrm{X}^{2}(8, N=204)=198.7, p<.001$} \\
\hline & Tilly & $X$ & NA & $X$ & & $(\mathrm{X})$ & $(\mathrm{X})$ & \\
\hline & Mickey & & NA & $\mathrm{X}$ & & & $(\mathrm{X})$ & \\
\hline \multirow{10}{*}{$\begin{array}{r}\text { (2) Young } \\
\text { adult kin and } \\
\text { mother } \\
\text { subgroup }\end{array}$} & Calli & NA & & & $\mathrm{X}$ & & $(\mathrm{X})$ & \multirow[t]{10}{*}{$\mathrm{X}^{2}(36, N=749)=1,354, p<.001$} \\
\hline & Dory & NA & $(\mathrm{X})$ & $\mathrm{X}$ & $\mathrm{X}$ & $X$ & $(\mathrm{X})$ & \\
\hline & Pigeon & NA & & $X$ & $(\mathrm{X})$ & & (X) & \\
\hline & Dixon & NA & $X$ & & & $X$ & $(\mathrm{X})$ & \\
\hline & Jack & NA & & $X$ & $\mathrm{X}$ & & (X) & \\
\hline & Ken & NA & & & $\mathrm{X}$ & $X$ & (X) & \\
\hline & Shawn & NA & & $X$ & & $X$ & (X) & \\
\hline & Stan & NA & $X$ & & $X$ & $X$ & (X) & \\
\hline & Tank & NA & $(\mathrm{X})$ & $\mathrm{X}$ & & $X$ & (X) & \\
\hline & Vin & NA & & $X$ & & $X$ & (X) & \\
\hline \multirow{5}{*}{$\begin{array}{r}\text { (3) Calf kin, } \\
\text { young adult } \\
\text { kin, and } \\
\text { mother } \\
\text { subgroup }\end{array}$} & Margarita & & & $X$ & & & $(\mathrm{X})$ & \multirow[t]{5}{*}{$\mathrm{X}^{2}(20, N=165)=430.6, p<.001$} \\
\hline & Poli & & & & $\mathrm{X}$ & $(\mathrm{X})$ & & \\
\hline & Anthony & & & $X$ & $X$ & & $(\mathrm{X})$ & \\
\hline & Champ & $X$ & & & $\mathrm{X}$ & & (X) & \\
\hline & Mac & & & $\mathrm{X}$ & & & $(\mathrm{X})$ & \\
\hline
\end{tabular}

Note: $\mathrm{X}=$ calf interacted significantly more than predicted from availability (positive residuals $>1.96),(\mathrm{X})=$ calf interacted significantly less than predicted from availability (negative residuals $<-1.96$ ), and blank = calf interacted according to availability. NA = category was not available to the calf. Note: the Young-kin group is a combination of three subgroups.

\section{Young-Kin Group and Differences Between Male and Female Calves}

Male and female calves had different patterns of initiating contact with the different kin and nonkin age categories; the interaction term of calf sex*kin and non-kin age categories was significant $\left(\mathrm{X}^{2}(3, N\right.$ 
$=1,118)=12.11, p=.007)$. Female calves had an overall probability of initiating interactions of 0.58 and this did not vary by kin and non-kin age categories $\left(\mathrm{X}^{2}(3, N=383)=3.62, p=.31\right)$. Female calves were less likely to initiate contact with their mothers but were more likely to initiate contact with young non-kin compared to the Mother-only group (primarily females, Table 3).

Males, in contrast, had different patterns of initiation depending on the kin and non-kin age categories $\left(\mathrm{X}^{2}(3, N=735)=14.94, p=.002\right)$. There was a continuum with overlapping $\mathrm{P}$ (initiator) of some of the different kin and non-kin age categories. Specifically, male calves initiated most contacts with their mothers $(0.72)$ and least with young dolphins ( 0.56 with kin, 0.54 with non-kin). P(initiator) with adult nonkin was 0.63 and was not different from the $\mathrm{P}$ (initiator) for mother $(p=.19)$ or young non-kin $(p=.19)$. Male calves were $33 \%$ more likely to initiate contact with their mothers than young dolphins (kin and nonkin combined).

\section{Discussion}

All individual calves shared the most pectoral fin contacts with their mother as predicted based on the strength of the mother-offspring bond for social mammals (Gibson \& Mann, 2008; Hill et al., 2007; Mann \& Smuts, 1998, 1999). Indeed, these calves initiated PFC exchanges with preferred partners (primarily their mothers) over individuals who were simply available to them (Table A1). This finding is consistent when contact with other young dolphins was also documented; in all cases for calf-initiated contacts, the majority of PFC was with the mother but when young kin were available, the calves shared less PFC with their mother to share PFC with other young dolphins. As one of the first studies to investigate calf-initiated tactile contact with the mother, other kin, and non-kin, these findings appear to be consistent with interactions that have been documented for dolphins (Gibson \& Mann, 2008; Krzyszczyk et al., 2017; Levengood \& Dudzinski, 2015).

For calves with mothers as their only kin available, there was a difference in how they shared PFC with non-kin adults versus non-kin young. A calf was twice as likely to initiate PFC with an adult (mother or adult non-kin) as with another young dolphin. Observations of nulliparous female Indo-Pacific bottlenose dolphins (T. aduncus) taking calves from their mothers (Mann \& Smuts, 1998) supports our finding of no difference between mothers and other adult non-kin for calf PFC initiations. Similarly, there was no difference in calf-initiated PFC with young non-kin of different ages (e.g., calf, juvenile, or subadult). For calves with young kin and their mothers available, there was no difference in how calves initiated PFC with young kin versus young non-kin. This finding would suggest that, at least for PFC, a peer of similar age does not rely on kinship for preference, which is supported by observations that young calves prefer similar age peers for play (Cappiello et al., 2018; Kuczaj \& Eskelinen, 2014; Kuczaj et al., 2006).

It seems likely that peer-group has an effect on the frequency of PFC shared by individual calves. In the current study, two calves, Fiona and Tank, were each born with no peers of similar age present in the group. As such, these two calves interacted more with older dolphins and might have represented a novelty to the rest of the group. That is, both Fiona and Tank received nearly twice as many PFCs as they initiated with non-kin older dolphins, which supports the notion that dolphin calves are enriching to all other aged members of a social group (Kuczaj et al., 2006; Kuczaj \& Eskelinen, 2014).

Though maternal influence on PFC exchange is strong for both calf sexes, male and female calves were different in how they initiated PFC with kin and non-kin. Male calves initiated PFC differently between kin and non-kin whereas female calves shared PFC similarly with kin and non-kin. Female calves generally initiated PFC slightly more with other young kin than with their mothers, especially when in groups with more kin available than just their mothers. Males shared PFC along a gradient with their mother most and then with both kin and non-kin young dolphins. These differences in PFC by males as compared with females hint at the sex-specific trends that are evident in some adult dolphin groups (Connor et al., 1992; Gerber et al., 2020; Mann et al., 2000; Smolker et al., 1992). Research conducted with the Shark Bay bottlenose dolphins has shown that early development of calf and juvenile social interaction foreshadows their adult associations, especially with same-sex, same-aged peers (Gerber et al., 2020; Krzyszczyk et al., 2017; Stanton et al., 2011), which seems also to be the case for these dolphins. Use of PFC tactile exchanges 
may be a factor for both male and female calves as they develop their own social networks within the group (Krzyszczyk et al., 2017), much as male associations with non-kin may be predictive of alliance formation in male dolphins (Gerber et al., 2020).

Specific to PFC, male and female calves may develop different patterns that might be predictive of their future patterns of tactile contact via the pectoral fin. Similar to adult free-ranging female dolphins (Furuichi et al., 2014), females in this managed care group do not share much tactile contact whereas males use PFC to establish and maintain their relationships with other males (Dudzinski \& Ribic, 2017). Perhaps other forms of contact, aside from PFC, are mediating tactile contacts between both sexes or one sex more than the other. For example, Kaplan and Connor (2007) described rough play involving aggressive head tactile contact as a potential precursor to male dominance interactions. Although we could not examine calf age as related to PFC exchanges, it would be interesting to further investigate if older, male, pre-weaned calves shared more PFC with older males than females. If so, this pattern could reflect a developmental trend toward the observed pattern of male-male PFC exchanges used as a tool for social bonding (Dudzinski \& Ribic, 2017).

\section{Kin vs. Non-Kin PFC Exchanges - General Patterns}

Our observations that PFCs shared by calves with kin and non-kin in differing patterns supports the notion that this type of tactile interaction and the subtle nuances that characterize its function within a fission-fusion society must be learned as an individual dolphin matures. Additionally, our observations confirm that though PFC is shared most between calves and their mothers as kin, it is a behavior shared less between kin than by non-kin (Connor, Mann et al., 2006; Dudzinski \& Ribic, 2017; Dudzinski et al., 2021). PFC is a tactile behavior that dolphins use to manage both subtle and overt signals when sharing information with peers, as well as when establishing and developing relationships in their social groups (Dudzinski \& Ribic, 2017). The message conveyed with a PFC can vary depending on the body part contacted, the participants' postures, who initiates, and who departs (Dudzinski et al., 2009, 2010, 2012). What is clear from these, and previous, studies is that PFC is primarily shared between non-kin rather than kin (Dudzinski \& Ribic, 2017; Dudzinski et al., 2021). Of the thousands of PFCs documented over 16 years of study less than $18 \%$ were shared by kin and less than half of those were shared by calves with both kin and non-kin partners. Thus, even though mothers and calves share the most PFC as kin (Dudzinski et al., 2021), it is likely that kin, including mothers and calves, siblings, or other relations, use different forms of contact more to share information. These other behaviors likely include body-body contact, various pair swims (Gubbins et al., 1999; Noren et al., 2008) that involve tactile components, or various postures and synchronous actions that allow dolphins to manage their relationships.

A society is comprised of relationships between individuals at multiple levels; two individuals will invest in their relationship that evolves over time depending on the frequency, consistency, and nature of their interactions (Hinde, 1976, Kummer, 1978). Each individual contributes differently to each relationship and the history of their exchanges allows assessment of their bond (Hinde, 1976, Kummer, 1978). One approach to examining relationships in a group is to assess association patterns measured via proximity, or membership, in the same group (see Cairns \& Schwager (1987) regarding association measures and Danaher-Garcia et al. (2019) for an example application of the half-weight measure). Another way to examine relationships is to look at a variety of behaviors shared between two individuals (i.e., more than PFCs) that could have direct benefit to the individuals involved in the relationship(s), as has been done for chimpanzees (Pan troglodytes, Fraser et al., 2008), ravens (Corvus corax, Fraser \& Bugnyar, 2010), and macaques (Macaca sylvanus, McFarland \& Majolo, 2011). Future research into dolphin-shared behaviors and their fission-fusion societies would benefit from an examination of the quality of the dyadic relationships in a study population.

\section{Acknowledgments}

Financial support for longitudinal data collection has been provided continuously by the Dolphin Communication Project (DCP). At the time of publication, the data have not been published by DCP but 
can be made available for examination. The Galindo Family and Anthony's Key Resort (AKR) provided logistical support that included lodging, food, and access to the dolphins during all years of study at the Roatan Institute for Marine Sciences (RIMS). DCP-organized eco-tours brought volunteers to AKR to assist with additional funding for data collection. Mystic Aquarium provided financial support towards data collection during 2004-2006. Eldon Bolton, RIMS Director, provided access to records for the dolphins under his supervision. Teri Bolton and the training team of RIMS provided much insight and discussion during and after observation sessions of the dolphins. Numerous interns and volunteers assisted with processing video data, with special thanks to A. Levengood, N. Danaher-Garcia, B. McIntosh, J. EvansWilent, W. Greene, and N. Batzel. K. Melillo-Sweeting, J. Gregg, H. Hill, and D. Rugg reviewed early drafts of this manuscript. D. Rugg provided valuable suggestions on statistical analyses. Any use of trade, product, or firm names is for descriptive purposes only and does not imply endorsement by the U.S. Government. This paper represents contribution \#125 of the Dolphin Communication Project.

\section{References}

Bender, C. E., Herzing, D. L., \& Bjorklund, D. F. (2009). Evidence of teaching in Atlantic spotted dolphins (Stenella frontalis) by mother dolphins foraging in the presence of their calves. Animal Cognition, 12(1), 43-53.

Brent, L. J., Franks, D. W., Foster, E. A., Balcomb, K. C., Cant, M. A., \& Croft, D. P. (2015). Ecological knowledge, leadership, and the evolution of menopause in killer whales. Current Biology, 25(6), 746-750.

Cairns, S. J., \& Schwager, S. J. (1987). A comparison of association indices. Animal Behaviour 35(5), 1454-1469.

Cappiello, B. M., Hill, H. M., \& Bolton, T. T. (2018). Solitary, observer, parallel, and social object play in the bottlenose dolphin (Tursiops truncatus). Behavioural Processes, 157, 453-458.

Connor, R. C., Mann, J., \& Watson-Capps, J. (2006). A sex-specific affiliative contact behavior in Indian Ocean bottlenose dolphins, Tursiops sp. Ethology, 112(7), 631-638.

Connor, R. C., Smolker, R., \& Bejder, L. (2006). Synchrony, social behaviour and alliance affiliation in Indian Ocean bottlenose dolphins, Tursiops aduncus. Animal Behaviour, 72(6), 1371-1378.

Connor, R. C., Smolker, R. A., \& Richards, A. F. (1992). Two levels of alliance formation among male bottlenose dolphins (Tursiops sp.). Proceedings of the National Academy of Sciences of the United States of America, 89(3), 987-990.

Cornell, L. H., Asper, E. D., Antrim, J. E., Searles, S. S., Young, W. G., \& Goff, T. (1987). Progress report: Results of a long-range captive breeding program for the bottlenose dolphin, Tursiops truncatus and Tursiops truncatus gilli. Zoo Biology, 6(1), 41-53.

Danaher-Garcia, N. A., Melillo-Sweeting, K., \& Dudzinski, K. M. (2019). Social structure of Atlantic spotted dolphins (Stenella frontalis) off Bimini, The Bahamas (2003-2016): Alternate reasons for preferential association in delphinids. Acta Ethologica, 23, 9-21.

Dudzinski, K. M., Clark, C. W., \& Würsig, B. (1995). A mobile video/acoustic system for simultaneous recording underwater recording of dolphin interactions. Aquatic Mammals, 21(2), 187-193.

Dudzinski, K. M., Gregg, J. D., Melillo-Sweeting, K., Levengood, A., Seay, B., \& Kuczaj II, S. A. (2012). Tactile contact exchanges between dolphins: Self-rubbing versus inter-individual contact in three species from three geographies. International Journal of Comparative Psychology - Special Symposium Issue, 25(1), 21-43.

Dudzinski, K. M., Gregg, J. D., Paulos, R. D., \& Kuczaj, S. A. (2010). A comparison of pectoral fin contact behaviour for three distinct dolphin populations. Behavioural Processes, 84(2), 559-567.

Dudzinski, K. M., Gregg, J. D., Ribic, C. A., \& Kuczaj, S. A. (2009). A comparison of pectoral fin contact between two different wild dolphin populations. Behavioural Processes, 80(2), 182-190.

Dudzinski, K. M., Danaher-Garcia, N., \& Gregg, J. D. (2013). Pectoral fin contact between dolphin dyads at Zoo Duisburg, with comparison to other dolphin study populations. Aquatic Mammals, 39(4), 335-343.

Dudzinski, K. M., \& Ribic, C. A. (2017). Pectoral fin contact as a mechanism for social bonding among dolphins. Animal Behavior \& Cognition, 4(1), 31-49.

Dudzinski, K. M., Ribic, C. A., Hill, H. M., \& Bolton, T. T. (2021). Evidence for maternal style in pectoral fin contact in dolphin. Animal Behavior and Cognition, 8(1), 52-68.

Edenbrow, M., \& Croft, D. P. (2012). Kin and familiarity influence association preferences and aggression in the mangrove killifish (Kryptolebias marmoratus). Journal of Fish Biology, 80(2), 503-518.

Evans-Wilent, J., \& Dudzinski, K. M. (2013). Vocalizations associated with pectoral fin contact in bottlenose dolphins (Tursiops truncatus). Behavioural Processes, 100, 74-81.

Fraser, O. N., \& Bugnyar, T. (2010). The quality of social relationships in ravens. Animal Behaviour, 79(4), 927-933. 
Fraser, O. N., Schino, G., \& Aureli, F. (2008). Components of relationship quality in chimpanzees. Ethology, 114(9), 834-843.

Furuichi, T., Connor, R., \& Hashimoto, C. (2014). Chapter 20, Non-conceptive sexual interactions in monkeys, apes, and dolphins. In J Yamagiwa \& L. Karczmarski (Eds.), Primates and cetaceans: Field research and conservation of complex mammalian societies (pp. 385-408). Springer.

Gerber, L., Connor, R. C., King, S., L., Allen, S. J., Wittwer, S., Bizzozzero, M. R., Friedman, W. R., Kalberer, S., Sherwin, W. B., Wild, S., Willems, E. P., \& Krützen, M. (2020). Affiliation history and age similarity predict alliance formation in adult male bottlenose dolphins. Behavioral Ecology, 31(2), 361-370.

Gibson, Q. A., \& Mann, J. (2008). Early social development in wild bottlenose dolphins: Sex differences, individual variation and maternal influences. Animal Behaviour, 76(2), 375-387.

Greene, W., Melillo-Sweeting, K., \& Dudzinski, K. M. (2011). Comparing object play in captive and wild dolphins. International Journal of Comparative Psychology, 24(3), 292-306.

Gubbins, C., McCowan, B., Lynn, S. K., Hooper, S., \& Reiss, D. (1999). Mother-infant spatial relations in captive bottlenose dolphins, Tursiops truncatus. Marine Mammal Science, 15(3), 751-765.

Guinet, C. (1991). Intentional stranding apprenticeship and social play in killer whales (Orcinus orca). Canadian Journal of Zoology, 69(11), 2712-2716.

Guinet, C., \& Bouvier, J. (1995). Development of intentional stranding hunting techniques in killer whale (Orcinus orca) calves at Crozet Archipelago. Canadian Journal of Zoology, 73(1), 27-33.

Hill, H. M., Greer, T., Solangi, M., \& Kuczaj, S.A. II. (2007). All mothers are not the same: Maternal styles in captive bottlenose dolphins. International Journal of Comparative Psychology, 20(1), 34-53.

Hinde, R. A. (1970). Animal behavior. (2 $2^{\text {nd }}$ ed.). McGraw-Hill.

Hinde, R. A. (1976). Interactions, relationships and social structure. Man, 11(1), 1-17.

Jaakkola, K., \& Willis, K. (2019). How long do dolphins live? Survival rates and life expectancies for bottlenose dolphins in zoological facilities vs. wild populations. Marine Mammal Science, 35(4), 1418-1437.

Janus, M. (1989). Reciprocity in play, grooming, and proximity in sibling and nonsibling young Rhesus monkeys. International Journal of Primatology, 10(3), 243-261.

Kaplan, J. D., \& Connor, R. C. (2007). A preliminary examination of sex differences in tactile interactions among juvenile Atlantic spotted dolphins (Stenella frontalis). Marine Mammal Science, 23(4), 943-953.

Kapsalis, E., \& Berman, C. M. (1996). Models of affiliative relationships among free-ranging Rhesus monkeys (Macaca mulatta) I. Criteria for kinship. Behaviour, 133(15/16), 1209-1234.

Kogi, K. Hishii, T., Imamura, A., Iwatani, T., \& Dudzinski, K. M. (2004). Demographic parameters of Indo-Pacific bottlenose dolphins (Tursiops aduncus) around Mikura Island, Japan. Marine Mammal Science, 20(3), 510526.

Krzyszczyk, E., Patterson, E. M., Stanton, M. A., \& Mann, J. (2017). The transition to independence: Sex differences in social and behavioural development of wild bottlenose dolphins. Animal Behaviour, 129, 43-59.

Kuczaj, S. A., \& Eskelinen, H. C. (2014). Why do dolphins play? Animal Behavior \& Cognition 1, 113-127.

Kuczaj, S. A., Makecha, R., Trone, M., Paulos, R. D., \& Ramos, J. A. (2006). Role of peers in cultural innovation and cultural transmission: Evidence from the play of dolphin calves. International Journal of Comparative Psychology, 19(2), 223-240.

Kuczaj, II, S. A., \& Yeater, D. B. (2007). Observations of rough-toothed dolphins (Steno bredanensis) off the coast of Utila, Honduras. Journal of the Marine Biological Association, U.K., 87, 141-148.

Kummer, H. (1978). On the value of social relationships to nonhuman primates: A heuristic scheme. Social Science Information, 17(4/5), 687-705.

Levengood, A. L., \& Dudzinski, K. M. (2015). Is blood thicker than water? The role of kin and non-kin in non-mothercalf associations of captive bottlenose dolphins (Tursiops truncatus). Behavioural Processes, 124, 52-59.

Lloyd, C. J. (1999). Statistical analysis of categorical data. Wiley and Sons.

Mann, J., Connor, R. C., Barre, L. M., \& Heithaus, M. R. (2000). Female reproductive success in bottlenose dolphins (Tursiops sp.): Life history, habitat, provisioning, and group-size effects. Behavioral Ecology, 11(2), 210219.

Mann, J., \& Smuts, B. B. (1998). Natal attraction: Allomaternal care and mother-infant separations in wild bottlenose dolphins. Animal Behaviour, 55(5), 1097-1113.

Mann, J. \& Smuts, B. (1999). Behavioral development in wild bottlenose dolphin newborns (Tursiops sp.). Behaviour, $136(5), 529-566$.

McCullagh, P., \& Nelder, J.A. (1989). Generalized linear models (2 $2^{\text {nd }}$ ed.). Chapman and Hall.

McFarland, R., \& Majolo, B. (2011). Exploring the components, asymmetry and distribution of relationship quality in wild Barbary macaques (Macaca sylvanus). PLoS ONE, 6(12), e28826. 
Miles, J. A., \& Herzing, D. L. (2003). Underwater analysis of the behavioural development of free-ranging Atlantic spotted dolphin (Stenella frontalis) calves (birth to 4 years of age). Aquatic Mammals, 29(3), 363-377.

Noren, S. R., Biedenbach, G., Redfern, J. V., \& Edwards, E. F. (2008). Hitching a ride: The formation locomotion strategy of dolphin calves. Functional Ecology, 22, 278-283.

Paulos, R. D., Trone, M., \& Kuczaj II, S. A. (2010). Play in wild and captive cetaceans. International Journal of Comparative Psychology, 23(4), 701-722.

Rugg, D. J. (2003). TableSim-A program for analysis of small-sample categorical data. Gen. Tech. Rep. NC-232. U.S. Department of Agriculture, Forest Service, North Central Research Station, St. Paul, MN

Sargeant, B., \& Mann, J. (2009). Developmental evidence for foraging traditions in wild bottlenose dolphins. Animal Behaviour, 78(3), 715-721.

Schino, G. (2001). Grooming, competition and social rank among female primates: A meta-analysis. Animal Behaviour, 62(2), 265-271.

Silk, J. B. (2002). Kin selection in primate groups. International Journal of Primatology, 23(4), 849-875.

Silva Jr, J. M., Silva, F. J., \& Sazima, I. (2005). Rest, nurture, sex, release, and play: Diurnal underwater behaviour of the spinner dolphin at Fernando de Noronha Archipelago, SW Atlantic. Journal of Ichthyology and Aquatic Biology, 9(4), 161-176.

Smolker, R. A., Richards, A. F., Connor, R. C., \& Pepper, J. W. (1992). Sex differences in patterns of association among Indian ocean bottlenose dolphins. Behaviour, 123(1/2), 38-69.

Stanton, M. A., Gibson, Q. A., \& Mann, J. (2011). When mum's away: A study of mother and calf ego networks during separations in wild bottlenose dolphins (Tursiops sp). Animal Behaviour, 82(2), 405-412.

Wells, R. S. (2014). Social structure and life history of common bottlenose dolphins near Sarasota Bay, Florida: Insights from four decades and five generations. In J. Yamagiwa \& L. Karczmarski (Eds.), Primates and cetaceans: Field research and conservation of complex mammalian societies (pp. 149-172). Springer.

Wells, R. S., Scott, M. D., \& Irvine, A. B. (1987). The social structure of free-ranging bottlenose dolphins. In H. H. Genoways (Ed.), Current mammalogy, Vol. 1. (pp. 247-305). Plenum Press.

Wu, C-F., Liao, Z-J., Sueur, C., Sha, J. C. M., Zhang, J., \& Zhang, P. (2018). The influence of kinship and dominance hierarchy on grooming partner choice in free-ranging Macaca mulatta brevicaudus. Primates, 59, 377-384. 


\section{Appendix}

\section{Table A1}

Proportions of Kin and Non-kin Age Groups Available for each of the 23 Bottlenose Dolphin Calves Analyzed in the Paper

\begin{tabular}{|c|c|c|c|c|c|c|c|}
\hline \multirow[b]{2}{*}{$\begin{array}{l}\text { Kin available } \\
\text { group }\end{array}$} & \multirow{2}{*}{ Calf } & \multicolumn{3}{|c|}{ Kin } & \multicolumn{3}{|c|}{ Non-kin } \\
\hline & & Calf & Young adult & Mother & Calf & Young adult & Adult \\
\hline \multirow{5}{*}{$\begin{array}{l}\text { Mother only } \\
\text { Group }\end{array}$} & Bailey & NA & NA & .063 & .284 & .243 & .410 \\
\hline & Fiona & NA & NA & .059 & .295 & .264 & .382 \\
\hline & Luna & NA & NA & .045 & .227 & .318 & .409 \\
\hline & Mika & NA & NA & .059 & .118 & .412 & .412 \\
\hline & French & NA & NA & .062 & .308 & .220 & .410 \\
\hline \multicolumn{8}{|l|}{$\begin{array}{l}\text { Young-kin } \\
\text { Group }\end{array}$} \\
\hline \multirow{3}{*}{$\begin{array}{l}\text { (1) Calf kin and } \\
\text { mother } \\
\text { subgroup }\end{array}$} & Maury & .031 & NA & .061 & .184 & .331 & .393 \\
\hline & Tilly & .037 & NA & .037 & .185 & .296 & .444 \\
\hline & Mickey & .020 & NA & .042 & .145 & .356 & .437 \\
\hline \multirow{10}{*}{$\begin{array}{r}\text { (2) Young adult } \\
\text { kin and mother } \\
\text { subgroup }\end{array}$} & Calli & NA & .017 & .041 & .222 & .209 & .510 \\
\hline & Dory & NA & .050 & .050 & .113 & .231 & .557 \\
\hline & Pigeon & NA & .042 & .042 & .165 & .314 & .437 \\
\hline & Dixon & NA & .078 & .051 & .169 & .331 & .371 \\
\hline & Jack & NA & .028 & .061 & .306 & .178 & .428 \\
\hline & Ken & NA & .061 & .061 & .306 & .144 & .428 \\
\hline & Shawn & NA & .084 & .048 & .133 & .217 & .518 \\
\hline & Stan & NA & .049 & .049 & .113 & .225 & .565 \\
\hline & Tank & NA & .069 & .069 & .117 & .186 & .558 \\
\hline & Vin & NA & .082 & .041 & .183 & .266 & .428 \\
\hline \multirow{5}{*}{$\begin{array}{l}\text { (3) Calf kin, } \\
\text { young adult kin, } \\
\text { and mother } \\
\text { subgroup }\end{array}$} & Margarita & .015 & .054 & .054 & .178 & .311 & .387 \\
\hline & Poli & .037 & .037 & .037 & .185 & .259 & .444 \\
\hline & Anthony & .033 & .033 & .067 & .200 & .233 & .433 \\
\hline & Champ & .019 & .025 & .085 & .188 & .196 & .489 \\
\hline & Mac & .019 & .042 & .042 & .188 & .177 & .532 \\
\hline
\end{tabular}

Note. The Young-kin group is a combination of three subgroups. NA = category was not available to the calf. Calf is a pre-weaned offspring younger than 4 years old. Young adult is an age category for analysis that includes both juvenile ( $\sim 3-\sim 7$ years) and subadult $(\sim 8-11$ years) individuals. 